Article

\title{
Prediction of Tacrolimus Exposure by CYP3A5 Genotype and Exposure of Co-Administered Everolimus in Japanese Renal Transplant Recipients
}

\author{
Hideaki Kagaya ${ }^{1}$, Takenori Niioka ${ }^{1}$, Mitsuru Saito ${ }^{2}$, Takamitsu Inoue ${ }^{2}{ }^{(D)}$, \\ Kazuyuki Numakura ${ }^{2}$, Ryohei Yamamoto ${ }^{2}$, Yumiko Akamine ${ }^{1}$, Tomonori Habuchi ${ }^{2}$, \\ Shigeru Satoh ${ }^{3}$ and Masatomo Miura ${ }^{1, *}$ \\ 1 Department of Pharmacy, Akita University Hospital, 1-1-1 Hondo, Akita 010-8543, Japan; \\ hideaki-kagaya@hos.akita-u.ac.jp (H.K.); t-niioka@hirosaki-u.ac.jp (T.N.); \\ yumiko-ai@hos.akita-u.ac.jp (Y.A.) \\ 2 Department of Urology, Akita University School of Medicine, 1-1-1 Hondo, Akita 010-8543, Japan; \\ mitsaito@med.akita-u.ac.jp (M.S.); takamitu@doc.med.akita-u.ac.jp (T.I.); \\ numakura@doc.med.akita-u.ac.jp (K.N.); yama815@med.akita-u.ac.jp (R.Y.); \\ thabuchi@doc.med.akita-u.ac.jp (T.H.) \\ 3 Center for Kidney Disease and Transplantation, Akita University Hospital, 1-1-1 Hondo, \\ Akita 010-8543, Japan; shigerus@doc.med.akita-u.ac.jp \\ * Correspondence: m-miura@hos.akita-u.ac.jp; Tel.: +81-18-884-6310; Fax: +81-18-836-2628
}

Received: 30 January 2018; Accepted: 12 March 2018; Published: 16 March 2018

\begin{abstract}
While tacrolimus and everolimus have common metabolic pathways through CYP3A4/5, tacrolimus is metabolized solely by CYP3A4 in recipients with the CYP3A5*3/*3. The purpose of this study was to evaluate how the area under the blood concentration-time curves (AUC) of tacrolimus could be predicted based on CYP3A5 genotype and the AUC of everolimus in renal transplant patients taking both drugs. The dose-adjusted AUC (AUC/D) of tacrolimus and everolimus were calculated at one month and one year after transplantation. Significant correlations between the AUC/D of tacrolimus and everolimus were found for patients with the $C Y P 3 A 5^{*} 1$ allele or $C Y P 3 A 5^{*} 3{ }^{*} 3$ at both one month and one year. At both stages, the determination coefficients were higher and the slopes of regression equations were larger for patients with $C Y P 3 A 5 * 3 / * 3$ compared to the CYP $3 A 5^{*} 1$ allele. A good correlation between single doses of tacrolimus and everolimus was found for $C Y P 3 A 5^{*} 3 / * 3$ patients at 1 year after transplantation $(r=0.794, p<0.001)$. The variability of the $\mathrm{AUC}_{0-24} / \mathrm{D}$ of tacrolimus for each CYP3A5 genotype could be predicted based on the $\mathrm{AUC}_{0-12} / \mathrm{D}$ of everolimus. Clinicians may be able to comprehensively carry out the dose adjustments of tacrolimus and everolimus based on relationship with AUCs of both drugs in each CYP3A5 genotype.
\end{abstract}

Keywords: tacrolimus; everolimus; CYP3A5 polymorphism; renal transplantation

\section{Introduction}

Tacrolimus, one of the calcineurin inhibitors (CNIs), displays high intra- and inter-individual pharmacokinetic variability and a poor correlation between dosage and drug blood concentration [1,2]. In addition, the therapeutic window of tacrolimus blood concentration is very narrow $[1,2]$. Hence, most clinicians prescribing tacrolimus use therapeutic drug monitoring (TDM) to guide dosing. Tacrolimus is mainly metabolized by cytochrome P450 (CYP) 3A4/5, which is expressed in the small intestine and hepatocytes, and the variability in tacrolimus pharmacokinetics has been attributed to individual differences in expression of the CYP3A4/5 protein [1,2]. The expression of CYP3A5 protein in the liver and small intestine is strongly correlated with a single nucleotide polymorphism, 6986A > G, 
within intron 3 of $C Y P 3 A 5$, designated $C Y P 3 A 5 * 3$ [3]. Tacrolimus pharmacokinetics is affected by the CYP3A5 polymorphism, as maintaining the same target blood concentration in recipients with CYP $3 A 5^{*} 3 / * 3$ requires a significantly lower dose of tacrolimus than in those with the CYP3A5*1 allele [4].

Recently, the addition of everolimus, a rapamycin derivative inhibitor of mTORi, into immunosuppressive therapy including tacrolimus has been used to reduce the risk of tacrolimus-induced nephrotoxicity in renal transplant recipients [5-9]. Everolimus also exhibits a narrow therapeutic window of blood concentration similar to tacrolimus [10]. Therefore, individualized dosage based on blood concentration is very important for renal transplant recipients taking tacrolimus and everolimus. Although everolimus is primarily metabolized by CYP3A4 and CYP3A5 [10], its pharmacokinetics are reported to be unaffected by CYP3A5 polymorphisms [11-13]. Thus, CYP3A4 rather than CYP3A5 is most likely the predominant enzyme involved in metabolic clearance of everolimus, whereas tacrolimus is metabolized by CYP3A5 rather than CYP3A4.

Tacrolimus [1,2] and everolimus [10] share a common metabolic pathway through CYP3A4/5; however, in patients with $C Y P 3 A 5^{*} 3 / * 3$, tacrolimus is metabolized solely by CYP3A4. The purpose of this study was to evaluate how the area under the blood concentration-time curve (AUC) of tacrolimus could be predicted based on CYP3A5 genotype and the AUCs of everolimus in renal transplant recipients taking both drugs.

\section{Results}

Clinical characteristics of the renal transplant recipients are listed in Table 1 . The allele frequencies for CYP3A5* 1 and ${ }^{*} 3$ at 1 month after renal transplantation $(n=50)$ were $30.0 \%$ and $70.0 \%$, respectively. Thirty-one of the 50 patients remained in the study 1 year after transplantation. The allele frequencies for $C Y P 3 A 5^{*} 1$ and ${ }^{*} 3$ at 1 year after renal transplantation $(n=31)$ were $25.0 \%$ and $75.0 \%$, respectively. The allele frequency of $C Y P 3 A 5^{*} 3$ was in Hardy-Weinberg equilibrium [14]. There were significant differences in clinical characteristics such as body weight, aspartate aminotransferase and serum albumin of patients between 1 month and 1 year after transplantation. None of the patients developed serious renal or hepatic dysfunction (Table 1).

Table 1. Clinical characteristics of patients after renal transplantation.

\begin{tabular}{lrlrl}
\hline Items & 1 Month after Transplantation & 1 Year after Transplantation \\
\hline Gender & & & & \\
Male & 30 & $(60.0 \%)$ & 20 & $(64.5 \%)$ \\
Female & 20 & $(40.0 \%)$ & 11 & $(35.5 \%)$ \\
Tacrolimus single dose $(\mathrm{mg})$ & 8.0 & $(5.0-12.0)$ & 4.0 & $(3.0-6.0)$ \\
Tacrolimus $\mathrm{C}_{0}(\mathrm{ng} / \mathrm{mL})$ & 7.0 & $(5.9-8.5)$ & 4.5 & $(4.0-6.0)$ \\
Everolimus single dose $(\mathrm{mg})$ & 0.75 & & 0.75 & $(0.50-0.75)$ \\
Everolimus $\mathrm{C}_{0}(\mathrm{ng} / \mathrm{mL})$ & 3.2 & $(2.4-4.1)$ & 3.5 & $(3.0-4.5)$ \\
Age (year) & 55.0 & $(47.0-61.0)$ & 58.0 & $(52.5-62.5)$ \\
Body weight $(\mathrm{kg})$ & 56.3 & $(47.2-63.3)$ & 59.9 & $(53.9-66.0)$ \\
Aspartate aminotransferase (IU/L) & 14 & $(11-17)$ & 22 & $(17-25)$ \\
Alanine aminotransferase (IU/L) & 14 & $(9-21)$ & 16 & $(12-24)$ \\
Hemoglobin $(\mathrm{g} / \mathrm{dL})$ & 10.4 & $(9.6-11.4)$ & 11.9 & $(10.8-13.3)$ \\
Serum albumin $(\mathrm{g} / \mathrm{dL})$ & 3.8 & $(3.5-4.0)$ & 4.1 & $(3.8-4.4)$ \\
Creatinine clearance $(\mathrm{mL} / \mathrm{min})$ & 50.3 & $(41.3-60.3)$ & 54.2 & $(39.4-63.9)$ \\
\hline CYP3A5 genotype & & & & \\
${ }^{*} 1 /{ }^{*} 1$ & 5 & $(10.0 \%)$ & 3 & $(9.7 \%)$ \\
${ }^{*} 1 /{ }^{* 3}$ & 20 & $(40.0 \%)$ & 10 & $(32.2 \%)$ \\
${ }^{*} 3 /{ }^{* 3}$ & 25 & $(50.0 \%)$ & 18 & $(58.1 \%)$ \\
\hline
\end{tabular}

The values are expressed as median (quartile 1-quartile 3 ) or number (\%) of patients. $C_{0}$, trough concentration. 
Comparison and correlation between the dose-adjusted $\mathrm{AUC}_{0-24}\left(\mathrm{AUC}_{0-24} / \mathrm{D}\right)$ or dose-adjusted $\mathrm{C}_{0}\left(\mathrm{C}_{0} / \mathrm{D}\right)$ of tacrolimus and each clinical characteristic of the patients, and the $\mathrm{AUC}_{0-12} / \mathrm{D}$ and $\mathrm{C}_{0} / \mathrm{D}$ of everolimus at 1 month and 1 year after transplantation are listed in Table 2 . There were significant differences in the $\mathrm{AUC}_{0-24} / \mathrm{D}$ and $\mathrm{C}_{0} / \mathrm{D}$ of tacrolimus among the 3 CYP3A5 genotypes at both 1 month and 1 year. In addition, there were also significant correlations with aspartate aminotransferase, alanine aminotransferase, and the $\mathrm{AUC}_{0-12} / \mathrm{D}$ or $\mathrm{C}_{0} / \mathrm{D}$ of everolimus 1 month after renal transplantation.

Although the $\mathrm{AUC}_{0-24} / \mathrm{D}$ and $\mathrm{C}_{0} / \mathrm{D}$ of tacrolimus were higher for patients with $\mathrm{CYP} 3 A 5^{*} 3 /{ }^{*}$ than those with the CYP3A5*1 allele at both 1 month (Figure 1a,b) and 1 year (Figure 2a,b) after transplantation, there were no differences in the corresponding parameters of everolimus at either time point (Figure 1c,d and Figure 2c,d).

(a)

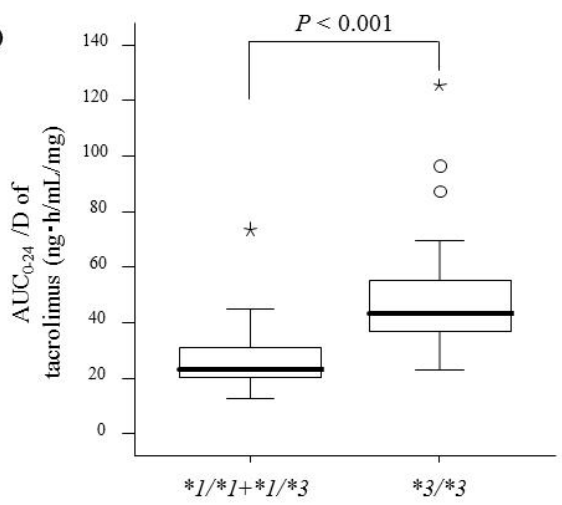

(c)

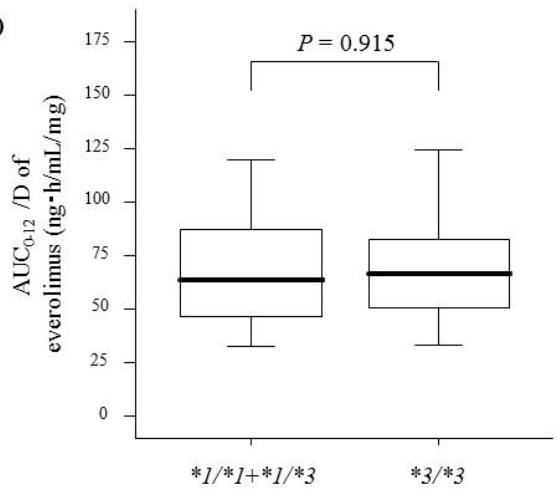

(b)

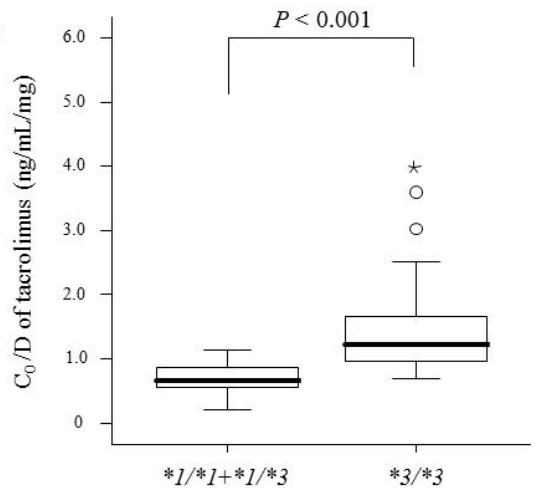

(d)

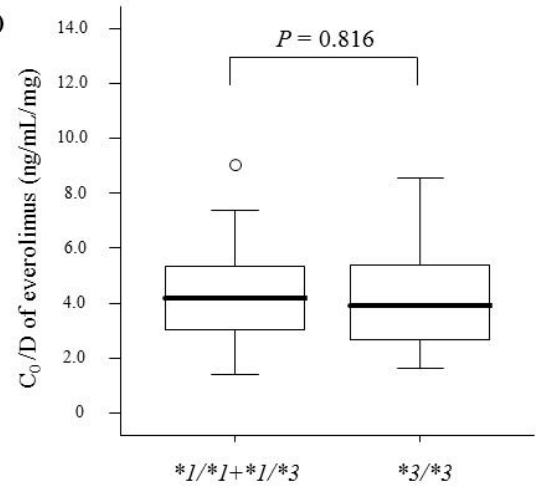

Figure 1. Comparison of dose-adjusted area under the blood concentration-time curves (AUC/D) and trough concentrations $\left(\mathrm{C}_{0} / \mathrm{D}\right)$ of tacrolimus and everolimus 1 month after renal transplantation between patients with CYP3A5*1 allele $(n=25)$ and ${ }^{*} 3{ }^{*} 3(n=25)$. Graphical analysis was performed using an SPSS box and whiskers plot. The box spans data between two quartiles (IQR), with the median represented as a bold horizontal line. The ends of the whiskers (vertical lines) represent the smallest and largest values that were not outliers. Outliers (circles) are values between 1.5 and 3 IQRs from the end of the box. Values more than three IQRs from the end of the box are defined as extreme (asterisk). (a) $\mathrm{AUC}_{0-24} / \mathrm{D}$ of tacrolimus; (b) $\mathrm{C}_{0} / \mathrm{D}$ of tacrolimus; (c) $\mathrm{AUC}_{0-12} / \mathrm{D}$ of everolimus; (d) $\mathrm{C}_{0} / \mathrm{D}$ of everolimus. 
Table 2. Comparison and correlation with the dose-adjusted $\mathrm{AUC}_{0-24}$ and $\mathrm{C}_{0}$ of tacrolimus and clinical characteristics of recipients.

\begin{tabular}{|c|c|c|c|c|c|c|c|c|}
\hline \multirow{2}{*}{ Tacrolimus } & \multicolumn{4}{|c|}{1 Month after Transplantation } & \multicolumn{4}{|c|}{1 Year after Transplantation } \\
\hline & $\mathrm{AUC}_{0-24} / \mathrm{D}(\mathrm{ng} \cdot \mathrm{h} / \mathrm{mL} / \mathrm{mg})$ & $p$-Value & $\mathrm{C}_{0} / \mathrm{D}(\mathrm{ng} / \mathrm{mL} / \mathrm{mg})$ & $p$-Value & $\mathrm{AUC}_{0-24} / \mathrm{D}(\mathrm{ng} \cdot \mathrm{h} / \mathrm{mL} / \mathrm{mg})$ & $p$-Value & $\mathrm{C}_{0} / \mathrm{D}(\mathrm{ng} / \mathrm{mL} / \mathrm{mg})$ & $p$-Value \\
\hline Gender & & 0.428 & & 0.663 & & 0.113 & & 0.261 \\
\hline Male & $35.8(23.1-46.6)$ & & $0.89(0.71-1.36)$ & & $59.0(30.4-73.7)$ & & $1.42(0.90-2.46)$ & \\
\hline Female & $32.2(22.8-39.2)$ & & $0.86(0.63-1.17)$ & & $34.9(30.6-48.1)$ & & $1.03(0.93-1.43)$ & \\
\hline CYP3A5 genotype & & $<0.001$ & & $<0.001$ & & $<0.001$ & & 0.019 \\
\hline${ }^{*} 1 /{ }^{*} 1$ & $20.3(15.7-22.3)$ & & $0.58(0.42-0.59)$ & & $27.5(26.6-29.2)$ & & $0.80(0.59-1.15)$ & \\
\hline${ }^{*} 1 /{ }^{*} 3$ & $26.0(21.3-31.3)$ & & $0.72(0.57-0.87)$ & & $30.6(27.3-37.7)$ & & $0.93(0.72-1.20)$ & \\
\hline \multirow[t]{2}{*}{$* 3 / * 3$} & $43.1(36.7-54.8)$ & & $1.20(0.97-1.66)$ & & $66.6(49.6-74.5)$ & & $1.63(1.03-2.67)$ & \\
\hline & Correlation coefficient $(r)$ & $p$-Value & Correlation coefficient $(r)$ & $p$-Value & Correlation coefficient $(r)$ & $p$-Value & Correlation coefficient $(r)$ & $p$-Value \\
\hline Age (year) & 0.219 & 0.127 & 0.236 & 0.100 & 0.345 & 0.058 & 0.307 & 0.092 \\
\hline Body weight (kg) & 0.021 & 0.883 & -0.018 & 0.903 & 0.038 & 0.839 & 0.122 & 0.515 \\
\hline Aspartate aminotransferase (IU/L) & 0.346 & 0.014 & 0.345 & 0.014 & 0.167 & 0.370 & -0.139 & 0.457 \\
\hline Alanine aminotransferase (IU/L) & 0.436 & 0.002 & 0.392 & 0.005 & 0.150 & 0.421 & -0.019 & 0.919 \\
\hline Hemoglobin $(\mathrm{g} / \mathrm{dL})$ & 0.145 & 0.315 & 0.274 & 0.054 & -0.024 & 0.900 & 0.008 & 0.965 \\
\hline Serum albumin (g/dL) & -0.014 & 0.921 & 0.073 & 0.615 & -0.156 & 0.401 & -0.141 & 0.448 \\
\hline Creatinine clearance $(\mathrm{mL} / \mathrm{min})$ & 0.116 & 0.423 & 0.115 & 0.426 & -0.259 & 0.160 & -0.054 & 0.772 \\
\hline Everolimus pharmacokinetics & $0.527^{*}$ & $<0.001$ & $0.526^{* *}$ & $<0.001$ & $0.442 *$ & 0.013 & $0.258 * *$ & 0.161 \\
\hline
\end{tabular}

The values are expressed as median (quartile 1-quartile 3) or correlation coefficient. $\mathrm{AUC}_{0-24}$, area under the concentration-time curve from 0 to $24 \mathrm{~h}$; $\mathrm{C}_{0}$, trough concentration; $\mathrm{D}$,

tacrolimus single dose; * vs. dose adjusted $\mathrm{AUC}_{0-12}$ of everolimus $(\mathrm{ng} \cdot \mathrm{h} / \mathrm{mL} / \mathrm{mg})$; ${ }^{* *}$ vs. dose-adjusted $\mathrm{C}_{0}$ of everolimus $(\mathrm{ng} / \mathrm{mL} / \mathrm{mg})$. 
(a)

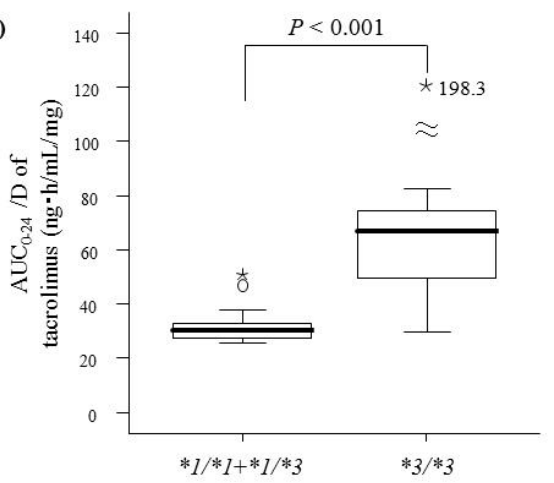

(c)

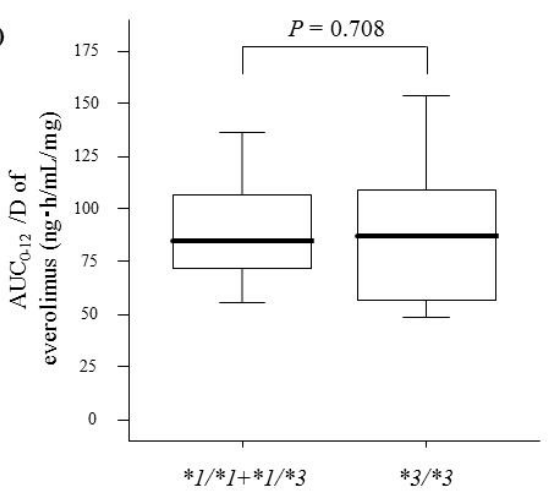

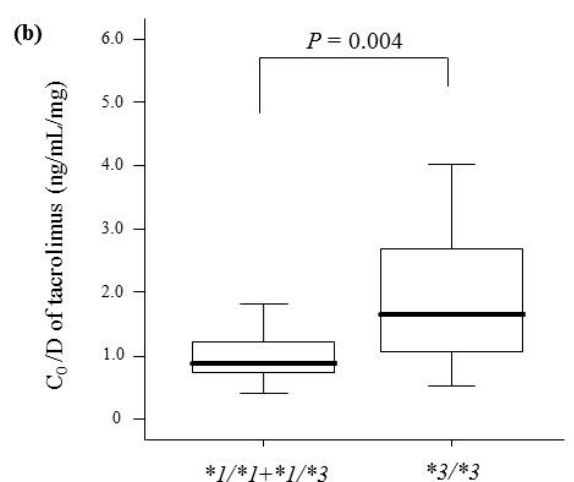

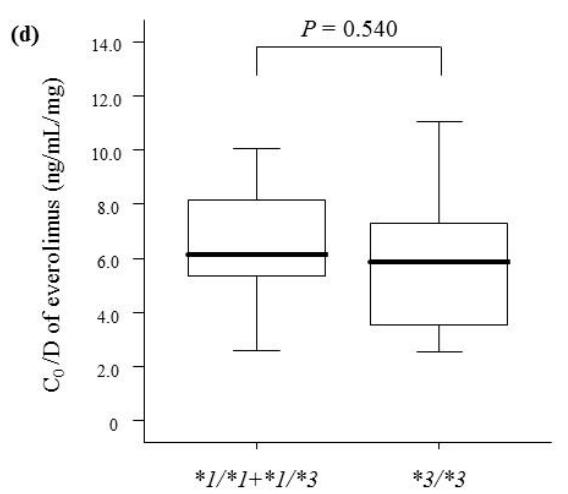

Figure 2. Comparison of the dose-adjusted area under the blood concentration-time curves (AUC/D) and trough concentrations $\left(C_{0} / D\right)$ of tacrolimus and everolimus 1 year after renal transplantation between patients with CYP3A5*1 allele $(n=13)$ and ${ }^{*} 3{ }^{*} 3(n=18)$. Graphical analysis was performed using an SPSS box and whiskers plot. The box spans data between two quartiles (IQR), with the median represented as a bold horizontal line. The ends of the whiskers (vertical lines) represent the smallest and largest values that were not outliers. Outliers (circles) are values between 1.5 and 3 IQRs from the end of the box. Values more than three IQRs from the end of the box are defined as extreme (asterisk). (a) $\mathrm{AUC}_{0-24} / \mathrm{D}$ of tacrolimus; (b) $\mathrm{C}_{0} / \mathrm{D}$ of tacrolimus; (c) $\mathrm{AUC}_{0-12} / \mathrm{D}$ of everolimus; (d) $\mathrm{C}_{0} / \mathrm{D}$ of everolimus.

Significant correlations between the $\mathrm{AUC}_{0-24} / \mathrm{D}$ of tacrolimus and $\mathrm{AUC}_{0-12} / \mathrm{D}$ of everolimus were found for patients with the CYP3A5*1 allele or CYP3A5*3/*3 at both 1 month and 1 year after transplantation (Figure 3). The determination coefficients $\left(R^{2}\right)$ were higher for patients with CYP3A5*3 ${ }^{*} 3$ than those with the CYP3A5 1 allele at both 1 month and 1 year after transplantation ( 0.578 vs. 0.417 and 0.587 vs. 0.396 , respectively, Figure $3 a, b)$. In addition, the slopes of regression equations were also larger for patients with $C Y P 3 A 5^{*} 3 / * 3$ than those with the CYP3A $5^{*} 1$ allele at both stages $\left(0.775\right.$ vs. $0.330,{ }^{\dagger} p=0.009$ and 0.864 vs. $0.194,{ }^{\ddagger} p=0.012$, respectively, Figure $\left.3 \mathrm{a}, \mathrm{b}\right)$.

Stepwise selection multiple linear regression analysis of explanatory variables for the $\mathrm{AUC}_{0-24} / \mathrm{D}$ and $\mathrm{C}_{0} / \mathrm{D}$ of tacrolimus at 1 month and 1 year after transplantation are shown in Table 3 . The $\mathrm{AUC}_{0-12} / \mathrm{D}$ and $\mathrm{C}_{0} / \mathrm{D}$ of everolimus and CYP3A5 genotype $\left(C Y P 3 A 5^{*} 3{ }^{*} 3\right)$ were independent factors influencing the $\mathrm{AUC}_{0-24} / \mathrm{D}$ or $\mathrm{C}_{0} / \mathrm{D}$ of tacrolimus at both stages (all $p<0.01$ ). The determination coefficients for the $\mathrm{AUC}_{0-24} / \mathrm{D}$ of tacrolimus at both stages were 0.6 and greater. 
(a)

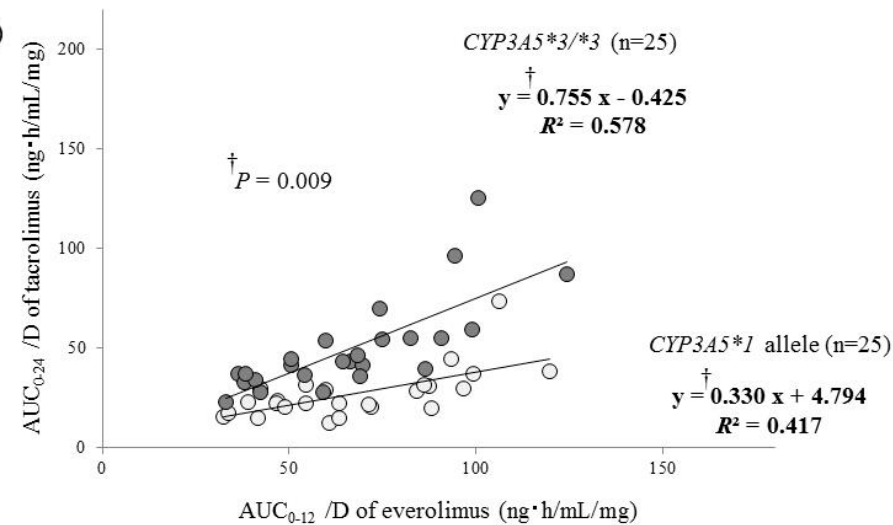

(b)

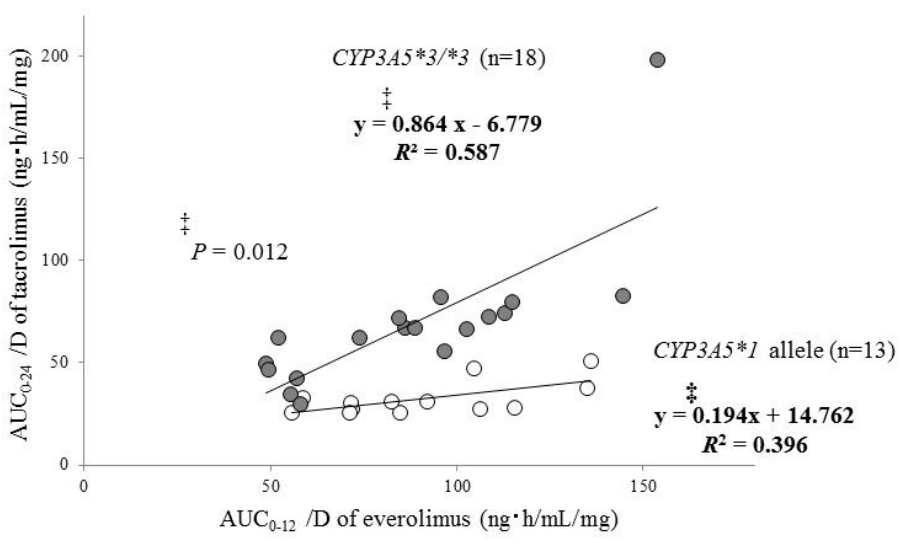

Figure 3. Correlation between the dose-adjusted area under the blood concentration-time curves of tacrolimus and everolimus. (a) one month after renal transplantation; (b) one year after renal transplantation. Open circles, patients with the $C Y P 3 A 5^{*} 1$ allele; closed circles, patients with the CYP $3 A 5^{*} 3 / * 3$.

Table 3. Stepwise multiple regression analysis of explanatory variables for the dose-adjusted $\mathrm{AUC}_{0-24}$ and $\mathrm{C}_{0}$ of tacrolimus.

\begin{tabular}{|c|c|c|c|c|c|c|}
\hline Objective Variable & Explanatory Variable & Slope & SE & SRC & $p$-Value & $R^{2}$ \\
\hline \multicolumn{6}{|c|}{$\mathrm{AUC}_{0-24} / \mathrm{D}$ of tacrolimus at 1 month after transplantation $(\mathrm{ng} \cdot \mathrm{h} / \mathrm{mL} / \mathrm{mg})$} & \multirow[t]{4}{*}{0.616} \\
\hline & $\mathrm{AUC}_{0-12} / \mathrm{D}$ of everolimus $(\mathrm{ng} \cdot \mathrm{h} / \mathrm{mL} / \mathrm{mg})$ & 0.534 & 0.083 & \multirow{3}{*}{$\begin{array}{l}0.581 \\
0.539\end{array}$} & \multirow{3}{*}{$\begin{array}{l}<0.001 \\
<0.001\end{array}$} & \\
\hline & CYP3A5 genotype $(* 3 / * 3=1)$ & 23.360 & 3.917 & & & \\
\hline & Intercept $=$ & -9.038 & 6.27 & & & \\
\hline \multicolumn{6}{|c|}{$\mathrm{C}_{0} / \mathrm{D}$ of tacrolimus at 1 month after transplantation $(\mathrm{ng} / \mathrm{mL} / \mathrm{mg})$} & \multirow[t]{4}{*}{0.643} \\
\hline & $\mathrm{C}_{0} / \mathrm{D}$ of everolimus $(\mathrm{ng} / \mathrm{mL} / \mathrm{mg})$ & 0.246 & 0.034 & 0.627 & $<0.001$ & \\
\hline & CYP3A5 genotype $(* 3 / * 3=1)$ & 0.792 & 0.135 & 0.510 & $<0.001$ & \\
\hline & Intercept $=$ & -0.379 & 0.181 & & & \\
\hline \multicolumn{6}{|c|}{$\mathrm{AUC}_{0-24} / \mathrm{D}$ of tacrolimus at 1 year after transplantation $(\mathrm{ng} \cdot \mathrm{h} / \mathrm{mL} / \mathrm{mg})$} & \multirow[t]{4}{*}{0.633} \\
\hline & CYP3A5 genotype $(* 3 / * 3=1)$ & 38.899 & 7.563 & 0.590 & $<0.001$ & \\
\hline & $\mathrm{AUC}_{0-12} / \mathrm{D}$ of everolimus $(\mathrm{ng} \cdot \mathrm{h} / \mathrm{mL} / \mathrm{mg})$ & 0.641 & 0.130 & 0.568 & $<0.001$ & \\
\hline & Intercept $=$ & -26.058 & 13.137 & & & \\
\hline \multicolumn{6}{|c|}{$\mathrm{C}_{0} / \mathrm{D}$ of tacrolimus at 1 year after transplantation $(\mathrm{ng} / \mathrm{mL} / \mathrm{mg})$} & \multirow[t]{4}{*}{0.427} \\
\hline & CYP3A5 genotype $(* 3 / * 3=1)$ & 0.943 & 0.252 & 0.539 & 0.001 & \\
\hline & $\mathrm{C}_{0} / \mathrm{D}$ of everolimus $(\mathrm{ng} / \mathrm{mL} / \mathrm{mg})$ & 0.160 & 0.053 & 0.435 & 0.005 & \\
\hline & Intercept = & -0.025 & 0.387 & & & \\
\hline
\end{tabular}

$\mathrm{AUC}_{0-24}$, and $\mathrm{AUC}_{0-12,}$ area under the concentration-time curve from 0 to $24 \mathrm{~h}$, and 0 to $12 \mathrm{~h} ; \mathrm{C}_{0}$, trough concentration; D, tacrolimus or everolimus single dose. SE, standard error; SRC, standardized regression coefficient. 
There were no changes in the $\mathrm{AUC}_{0-24} / \mathrm{D}$ of tacrolimus from day 14 (without everolimus) to day 28 (with everolimus) for patients with either the CYP3A5*1 allele or $C Y P 3 A 5^{*} 3 /{ }^{*} 3$ (Figure $4 a, b$ ).
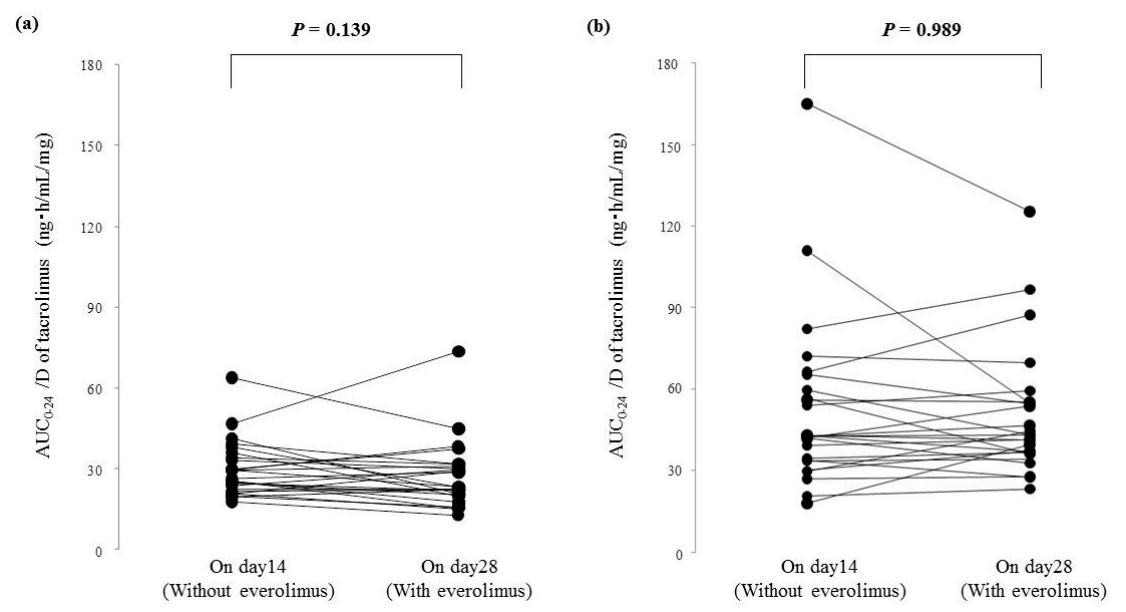

Figure 4. Comparison of the dose-adjusted area under the blood concentration-time curve from 0 to $24 \mathrm{~h}\left(\mathrm{AUC}_{0-24}\right)$ of tacrolimus between day 14 and day 28 after renal transplantation. (a) Patients with the CYP3A5*1 allele; (b) patients with the CYP3A5*3/*3.

Correlations with the dose-adjusted maximal plasma concentration $\left(C_{\max } / D\right)$ or the elimination half-life between tacrolimus and everolimus in patients with the CYP3A5 ${ }^{*} 1$ allele or CYP3A5*3/*3 at 1 month and 1 year after renal transplantation are listed in Table 4. At both stages, the $r$ of the $C_{\max } / \mathrm{D}$ or the elimination half-life were higher for patients with $C Y P 3 A 5^{*} 3 /{ }^{*} 3$ than those with the CYP3A $5^{*} 1$ allele, and the $r$ of $C_{\max } / \mathrm{D}$ in each CYP3A5 genotype was higher than those of the elimination half-life $\left(0.603>0.459\right.$ for $C Y P 3 A 5^{*} 1$ allele and $0.659>0.587$ for $C Y P 3 A 5^{*} 3 /{ }^{*} 3$ at 1 month; $0.349>0.099$ and $0.769>0.341$ at 1 year, respectively).

Table 4. Correlation between the dose-adjusted $C_{\max }$ and elimination half-life of tacrolimus and everolimus in each CYP3A5 genotype at 1 month and 1 year after renal transplantation.

\begin{tabular}{|c|c|c|c|c|}
\hline \multirow{2}{*}{$\begin{array}{l}\text { CYP3A5 } \\
\text { Genotype }\end{array}$} & \multicolumn{2}{|l|}{$\mathrm{C}_{\max } / \mathrm{D}$} & \multicolumn{2}{|c|}{ Elimination Half-Life } \\
\hline & Correlation Coefficient $(r)$ & $p$-Value & Correlation Coefficient $(r)$ & $p$-Value \\
\hline \multicolumn{5}{|c|}{1 month after transplantation } \\
\hline CYP3A5*1allele & 0.603 & $<0.001$ & 0.459 & 0.021 \\
\hline$* 3 / * 3$ & 0.659 & $<0.001$ & 0.587 & 0.002 \\
\hline \multicolumn{5}{|c|}{1 year after transplantation } \\
\hline CYP3A5*1allele & 0.349 & 0.243 & 0.099 & 0.748 \\
\hline$* 3 / * 3$ & 0.769 & $<0.001$ & 0.341 & 0.181 \\
\hline
\end{tabular}

$\mathrm{C}_{\max }$, maximum blood concentration; $\mathrm{D}$, tacrolimus single dose; $r$, tacrolimus vs. everolimus in $\mathrm{C}_{\max }$ or half-life.

At 1 year after renal transplantation, there was no correlation between single doses of tacrolimus and everolimus in patients with the CYP3A5 ${ }^{*} 1$ allele (Figure $5 \mathrm{a}, r=-0.073, p=0.813$ ); however, a significant correlation was found in patients with the CYP3A5*3/*3 (Figure $5 b, r=0.794, p<0.001$ ). 
(a)

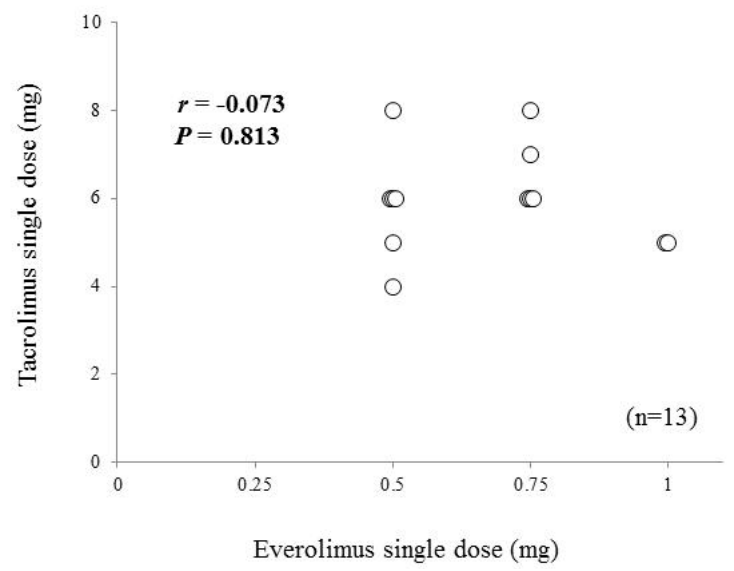

(b)

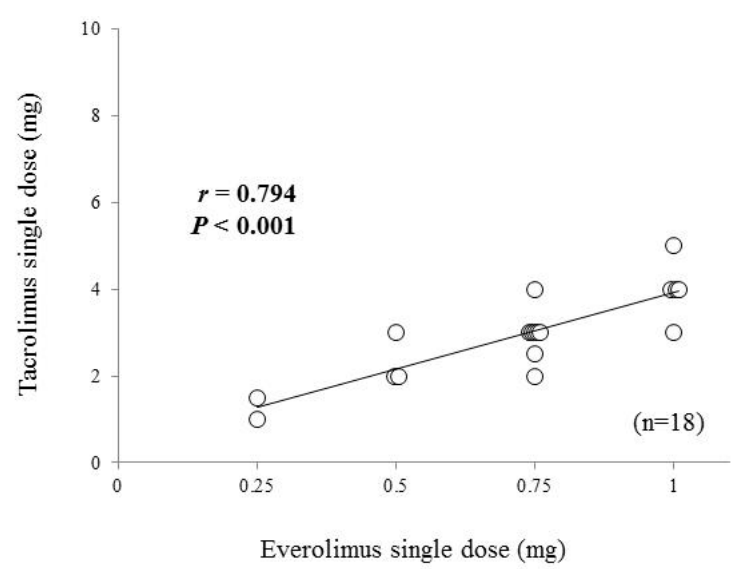

Figure 5. Correlation between the doses of tacrolimus and everolimus 1 year after renal transplantation. (a) Patients with the $C Y P 3 A 5^{*} 1$ allele; (b) patients with the $C Y P 3 A 5^{*} 3{ }^{*} 3$.

\section{Discussion}

In the present study at 1 month and 1 year after renal transplantation, $61.6 \%$ and $63.3 \%$, respectively, of the variability of the $\mathrm{AUC}_{0-24} / \mathrm{D}$ of tacrolimus were predicted by the combination of CYP3A5 genotype and $\mathrm{AUC}_{0-12} / \mathrm{D}$ of everolimus. These findings show that the individual AUC of tacrolimus at steady-state can be roughly approximated based on CYP3A5 activity and the activity of CYP3A4 as a marker of everolimus AUC.

Prior to and after everolimus co-administration, there were no significant differences in the $\mathrm{AUC}_{0-24} / \mathrm{D}$ of tacrolimus for patients with either the CYP3A5*1 allele or $C Y P 3 A 5^{*} 3 /{ }^{*}$. We have previously reported that there is no drug interaction between tacrolimus and everolimus affecting pharmacokinetics [15]. In addition, the pharmacokinetics of everolimus are not influenced by CYP3A5 polymorphisms $[11,13,16]$. Clinicians may be able to predict the $\mathrm{AUC}_{0-24} / \mathrm{D}$ of tacrolimus based on assessment of CYP3A4 activity by using the $\mathrm{AUC}_{0-24} / \mathrm{D}$ of everolimus, because a drug interaction via CYP3A4/ 5 does not seem to occur with a combination of these drugs. On the other hand, midazolam is used as the gold standard probe for in vivo CYP3A4 phenotyping $[17,18]$. De Jonge et al. reported that about $60 \%$ of the variability of the $\mathrm{AUC}_{0-24} / \mathrm{D}$ of tacrolimus can be explained by CYP3A5 genotype and apparent oral clearance of midazolam [19]. In addition, they reported that the pharmacokinetics of tacrolimus in the first year after renal transplantation in patients with the CYP3A $5^{*} 3 / 3$ could partly be explained by CYP3A4 activity based on the pharmacokinetics of midazolam and haematocrit [20]. This report supports our results. Similar to tacrolimus, everolimus is extensively bound to red blood cells [10]. Because an affector for red blood cell count is included in blood concentrations of everolimus, hemoglobin might not be an independent factor explaining the variability of the $\mathrm{AUC}_{0-24} / \mathrm{D}$ of tacrolimus in the present study. In patients taking tacrolimus, everolimus may play a role as an indicator of CYP3A4 activity.

The $\mathrm{AUC}_{0-24} / \mathrm{D}$ of tacrolimus was low in patients with a low $\mathrm{AUC}_{0-12} / \mathrm{D}$ of everolimus at 1 month and 1 year after renal transplantation (Figure 3). Therefore, such patients should be carefully monitored to prevent acute rejection. On the other hand, the $\mathrm{AUC}_{0-24} / \mathrm{D}$ of tacrolimus was high in patients with a higher $\mathrm{AUC}_{0-12} / \mathrm{D}$ of everolimus, and this tendency was more pronounced in patients with CYP3A5*3/*3 than those with the $C Y P 3 A 5^{*} 1$ allele. In patients with the $C Y P 3 A 5^{*} 1$ allele, tacrolimus is metabolized by both CYP3A4 and CYP3A5, whereas in patients with $C Y P 3 A 5^{*} 3{ }^{*} 3$, tacrolimus is solely metabolized by CYP3A4. Therefore, patients with a higher $\mathrm{AUC}_{0-12} / \mathrm{D}$ of everolimus and the $C Y P 3 A 5^{*} 3 /{ }^{*} 3$ need to be especially carefully monitored for tacrolimus-induced side effects. Shihab et al. have reported that an everolimus trough concentration of $3.8 \mathrm{ng} / \mathrm{mL}$ is needed to preserve a balance of efficacy and safety in the maintenance phase after renal transplantation for patients taking 
a low dose of tacrolimus [9]. Interestingly, in the present study, the correlation between the daily doses of tacrolimus and everolimus at 1 year after renal transplantation was extremely high in patients with CYP $3 A 5^{*} 3 / * 3$ (Figure $3 b$ ). Since clinicians adjust the daily dose of tacrolimus and everolimus based on their blood concentrations considering the efficacy and safety for immunosuppressive drugs through 1 year after transplantation, a good correlative relationship between the daily doses of tacrolimus and everolimus might be observed.

At 1 month and 1 year after renal transplantation, the correlation coefficients between the $C_{\max } / D$ or the elimination half-life of tacrolimus and everolimus were higher for patients with $C Y P 3 A 5^{*} 3 /{ }^{*}$ than those with the $C Y P 3 A 5^{*} 1$ allele, and the correlation coefficients of $C_{\max } / D$ were higher than those of elimination half-life for each CYP3A5 genotype. In addition, we have reported that the larger inter-individual variability of tacrolimus bioavailability for oral formulations is influenced by CYP3A5 polymorphism [21]. These results suggest that the inter-individual variability of tacrolimus pharmacokinetics in patients without CYP3A5 activity depends strongly on CYP3A4 activity in the small intestine. On the other hand, significant differences in body weight, aspartate aminotransferase and serum albumin of recipients between 1 month and 1 year after renal transplantation were found. However, in our previous study [22], the $\mathrm{AUC}_{0-24} / \mathrm{D}$ and $\mathrm{C}_{0} / \mathrm{D}$ of tacrolimus were unaffected by these factors. Therefore, these differences in each stage do not affect the interpretation of the results in this study.

Tacrolimus and everolimus are substrates of the drug transporter $P$-glycoprotein $[1,2,10]$. In the present study, we did not assess the activity of $P$-glycoprotein; however, our results may indicate an influence of $P$-glycoprotein, although it is unclear how much pharmacokinetic variability of either drug is related to $P$-glycoprotein. Vanhove et al. reported that the pharmacokinetic parameters of fexofenadine, a substrate of $P$-glycoprotein, were not predictive of tacrolimus oral clearance [23]. On the other hand, there is not enough evidence that $A B C B 1$ polymorphisms are useful as a factor in dose adjustment for tacrolimus $[24,25]$ or everolimus $[11,26]$. Therefore, further studies addressing this topic might be necessary. However, as shown in Figure 5, a good correlation between the single dose of tacrolimus and everolimus was found in patients with $C Y P 3 A 5^{*} 3 /{ }^{*} 3$ in the maintenance phase after renal transplantation. As to our protocol, when everolimus is added to the regimen of patients taking tacrolimus, clinicians may be able to individualize the initial dose of everolimus based on the $\mathrm{AUC}_{0-24} / \mathrm{D}$ or $\mathrm{C}_{0} / \mathrm{D}$ of tacrolimus and knowledge of the CYP3A5 genotype. However, further study of this approach is necessary.

Our results could be interpreted within the context of the study limitations. The present study was retrospectively performed with a small patient group in a non-controlled single-center study. In addition, the effect of pharmacokinetics of tacrolimus or everolimus on clinical outcome was not analyzed. Hence, additional studies with larger sample sizes might be necessary.

In conclusion, the variability of the $\mathrm{AUC}_{0-24} / \mathrm{D}$ of tacrolimus for each CYP3A5 genotype could be predicted based on the $\mathrm{AUC}_{0-12} / \mathrm{D}$ of everolimus. This finding seems to show that everolimus AUC might reflect an impact of CYP3A4 activity on tacrolimus AUC. Indicators of the CYP3A5 genotype and everolimus AUC may be especially useful for evaluating the metabolic activity of CYP3A4/5 for tacrolimus in the small intestine. For renal transplant recipients, clinicians may be able to comprehensively carry out dose adjustments of tacrolimus and everolimus based on the relationship of AUCs of both drugs in each CYP3A5 genotype.

\section{Materials and Methods}

\subsection{Patients and Protocols}

This retrospective study enrolled 50 Japanese renal transplant recipients who received renal grafts between October 2013 and March 2017 and were administered tacrolimus (modified-release once-daily formulation (Graceptor ${ }^{\circledR}$, Astellas, Tokyo, Japan)) and everolimus (Certican ${ }^{\circledR}$, Novartis Pharma, Tokyo, Japan). The study protocol was approved by the Ethics Committee of Akita University 
School of Medicine (Protocol No. 1248, 25 November 2014), and all patients gave written informed consent. The patient eligibility criteria for the study were (1) a tacrolimus-based immunosuppressive

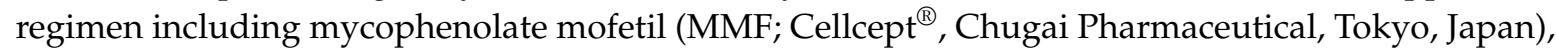
basiliximab, and steroid; (2) an absence of pre-transplant donor-specific antibodies or delayed graft function; (3) no severe liver dysfunction or gastrointestinal motility; and (4) no introduction of drugs or foods that obviously affect CYP3A function during the study period. All patients received rabeprazole and the sulfamethoxazole-trimethoprin drug combination. Patients initially received a combination immunosuppressive therapy regimen of tacrolimus and MMF 2 days prior to renal transplantation. An initial oral dose $(0.20 \mathrm{mg} / \mathrm{kg})$ of tacrolimus was given every $24 \mathrm{~h}$ at a designated time (09:00). Patients received a $24 \mathrm{~h}$ continuous intravenous infusion (CIV) of tacrolimus $(0.05 \mathrm{mg} / \mathrm{kg} /$ day) beginning on the day of transplantation until day 3. On day 3, tacrolimus administration was changed from CIV to oral administration. An initial oral dose of MMF $1500 \mathrm{mg} /$ day was given in equally divided doses every $12 \mathrm{~h}$ at designated times (09:00 and 21:00). On day 14, immediately after blood collection for tacrolimus analysis, everolimus was added to the above combination therapy at an initial dose of $1.5 \mathrm{mg} /$ day in equally divided doses every $12 \mathrm{~h}$ at designated times (09:00 and 21:00). The target $\mathrm{C}_{0}$ of tacrolimus was $15-20 \mathrm{ng} / \mathrm{mL}$ during CIV, $10-12 \mathrm{ng} / \mathrm{mL}$ during the first week, $8-10 \mathrm{ng} / \mathrm{mL}$ during the second to fourth week after renal transplantation, and $5-8 \mathrm{ng} / \mathrm{mL}$ thereafter. The target $\mathrm{C}_{0}$ of everolimus was $3-5 \mathrm{ng} / \mathrm{mL}$ after the second week. All patients received a controlled hospital diet served daily at 7:30, 12:30, and 18:00 in the hospital for the pharmacokinetic study.

\subsection{Sample Collection and Analytical Methods}

After renal transplantation, serial whole blood samples were collected in EDTA-2Na tubes just prior to the morning doses of tacrolimus and everolimus. An initial TDM of everolimus was carried out the second week after the start of administration. Blood samples for tacrolimus and everolimus analysis were collected just prior to and 1, 2, 3, 4, 6, 12, and $24 \mathrm{~h}$ after the morning doses (blood collection $24 \mathrm{~h}$ after drug administration was carried out only for tacrolimus) on day 14 (blood collection on day 14 was carried out only for tacrolimus), on day 28 (at 1 month), and at 1 year. Blood samples of tacrolimus and everolimus were collected just prior to the morning doses every month during the follow-up period. Blood concentrations of tacrolimus were determined by the chemiluminescence magnetic microparticle immunoassay (CLIA) on the Architect-i1000 ${ }^{\circledR}$ system (Abbott Laboratories; Abbott Park, IL, USA) according to the manufacturer's instructions. Blood concentrations of everolimus were determined by the latex agglutination turbidimetric immunoassay (LTIA) on the CA- $90^{\circledR}$ chemistry analyzer (Furuno Electric Company, Nishinomiya, Japan) according to the manufacturer's instructions.

\subsection{Genotyping}

DNA was extracted from whole blood samples before renal transplantation in 50 recipients with a QIAamp Blood Kit (Qiagen, Hilden, Germany) and was stored at $-80{ }^{\circ} \mathrm{C}$ until being analyzed. For genotyping the CYP3A5 6986A > G (*3), the polymerase chain reaction-restriction fragment length polymorphism (PCR-RFLP) method was used. PCR was performed with a $20 \mu \mathrm{L}$ aliquot containing $50 \mathrm{ng}$ of genomic DNA, 50 pmol of each primer, $80 \mu \mathrm{M}$ of each deoxynucleotide triphosphate, 0.6 units of Ampli-Taq Gold DNA polymerase, $1.2 \mathrm{mM} \mathrm{MgCl}$, and $1 \times$ reaction buffer (Applied Biosystems, Foster City, CA, USA). The primers used were as follows: forward, 5'-ATGGAGAGTGGCATAGGAGATA-3'; reverse, 5'-TGTGGTCCAAACAGGGAAGAAATA-3' . PCR amplification conditions were 8 min of initial denaturation at $94{ }^{\circ} \mathrm{C}$, followed by 40 cycles of melting at $94{ }^{\circ} \mathrm{C}$ for $30 \mathrm{~s}$, annealing at $55^{\circ} \mathrm{C}$ for $30 \mathrm{~s}$, and elongation at $72{ }^{\circ} \mathrm{C}$ for $30 \mathrm{~s}$, followed by a final elongation for $10 \mathrm{~min}$ at $72{ }^{\circ} \mathrm{C}$. The PCR products were digested at $37^{\circ} \mathrm{C}$ overnight with 10 units of SspI (New England Biolabs, Inc., Beverly, MA, USA). Digested products were separated on $2.5 \%$ agarose gel containing ethidium bromide. When the A allele (CYP3A5*1 allele) was present, the $130 \mathrm{bp}$ PCR fragment was divided into $107 \mathrm{bp}$ and $23 \mathrm{bp}$ fragments [27]. The analysis results obtained from 
PCR-RFLP were confirmed with a fully automated single nucleotide polymorphism (SNP) detection system (prototype i-densy ${ }^{\circledR}$, Arkray Inc., Kyoto, Japan).

\subsection{Pharmacokinetic Analysis}

Pharmacokinetic analyses of tacrolimus and everolimus were carried out using the standard non-compartmental method with Phoenix WinNonlin Version 6.4 (Pharsight Co., Mountain View, $\mathrm{CA}, \mathrm{USA}$ ). The AUC from 0 to $12 \mathrm{~h}$ (for everolimus) and 0 to $24 \mathrm{~h}$ (for tacrolimus) were calculated using the linear trapezoidal rule. The $\mathrm{C}_{\max }$ of tacrolimus was obtained directly from the profile. The elimination half-life of tacrolimus was obtained using log-linear regression of the terminal phase of the concentration-time data with at least three sampling points.

\subsection{Statistical Procedures}

The Shapiro-Wilk test was used to assess distribution. The characteristics of renal transplant recipients and parameters for tacrolimus and everolimus were expressed as medians (quartile 1-quartile 3). The Kruskal-Wallis test or Mann-Whitney $U$ test was used to determine the difference in continuous values between groups. The chi-square test was used to examine differences in categorical data, except when the expected number of cells was $<5$, in which case Fisher's exact test was used. The analysis of covariance was used to examine the parallelism of slopes between two regression equations. The Wilcoxon signed-rank test was used to determine the inter-patient difference in continuous values. Spearman's rank correlation coefficient test was used to assess correlations in continuous values between groups, and all results were expressed as a correlation coefficient of determinant $(r)$. Stepwise multiple linear regression analysis was performed to determine the effect of all factors in a univariate analysis. For each patient, the CYP3A5 genotype was replaced with dummy variables ( 1 and 0,0 and 1 , and 0 and 0 , respectively). The percent variation that could be explained by the multiple regression equation was expressed as a coefficient of determination $\left(R^{2}\right)$. A $p$-value less than 0.05 was considered statistically significant. Statistical analysis was performed with SPSS 20.0 for Windows (SPSS IBM Japan Inc., Tokyo, Japan).

Acknowledgments: This work was supported by a grant (No. 26460189) from the Japan Society for the Promotion of Science, Tokyo, Japan.

Author Contributions: Hideaki Kagaya and Masatomo Miura participated in the research design, performance of the research, data analysis and the writing of the paper; Takenori Niioka and Mitsuru Saito participated in the performance of the research and data analysis; and Takamitsu Inoue, Kazuyuki Numakura, Ryohei Yamamoto, Yumiko Akamine, Tomonori Habuchi, and Shigeru Satoh participated in the research design and performance of the research.

Conflicts of Interest: The authors declare no conflict of interest.

\section{References}

1. Staatz, C.E.; Tett, S.E. Clinical pharmacokinetics and pharmacodynamics of tacrolimus in solid organ transplantation. Clin. Pharmacokinet. 2004, 43, 623-653. [CrossRef] [PubMed]

2. Staatz, C.E.; Tett, S.E. Clinical Pharmacokinetics of Once-Daily Tacrolimus in Solid-Organ Transplant Patients. Clin. Pharmacokinet. 2015, 54, 993-1025. [CrossRef] [PubMed]

3. Hustert, E.; Haberl, M.; Burk, O.; Wolbold, R.; He, Y.Q.; Klein, K.; Nuessler, A.C.; Neuhaus, P.; Klattig, J.; Eiselt, R.; et al. The genetic determinants of the CYP3A5 polymorphism. Pharmacogenetics 2001, 11, 773-779. [CrossRef] [PubMed]

4. Birdwell, K.A.; Decker, B.; Barbarino, J.M.; Peterson, J.F.; Stein, C.M.; Sadee, W.; Wang, D.; Vinks, A.A.; He, Y.; Swen, J.J.; et al. Clinical Pharmacogenetics Implementation Consortium (CPIC) Guidelines for CYP3A5 Genotype and Tacrolimus Dosing. Clin. Pharmacol. Ther. 2015, 98, 19-24. [CrossRef] [PubMed]

5. Chan, L.; Greenstein, S.; Hardy, M.A.; Hardy, M.A.; Hartmann, E.; Bunnapradist, S.; Cibrik, D.; Shaw, L.M.; Munir, L.; Ulbricht, B.; et al. Multicenter, randomized study of the use of everolimus with tacrolimus after renal transplantation demonstrates its effectiveness. Transplantation 2008, 85, 821-826. [CrossRef] [PubMed] 
6. Chan, L.; Hartmann, E.; Cibrik, D.; Cooper, M.; Shaw, L.M. Optimal everolimus concentration is associated with risk reduction for acute rejection in de novo renal transplant recipients. Transplantation 2010, 90, 31-37. [CrossRef] [PubMed]

7. Langer, R.M.; Hené, R.; Vitko, S.; Christiaans, M.; Tedesco-Silva, H., Jr.; Ciechanowski, K.; Cassuto, E.; Rostaing, L.; Vilatoba, M.; Machein, U.; et al. Everolimus plus early tacrolimus minimization: A phase III, randomized, open-label, multicentre trial in renal transplantation. Transpl. Int. 2012, 25, 592-602. [CrossRef] [PubMed]

8. Sageshima, J.; Ciancio, G.; Chen, L.; Dohi, T.; El-Hinnawi, A.; Paloyo, S.; Misawa, R.; Ekwenna, O.; Yatawatta, A.; Burke, G.W., III. Everolimus with low-dose tacrolimus in simultaneous pancreas and kidney transplantation. Clin. Transplant. 2014, 28, 797-801. [CrossRef] [PubMed]

9. Shihab, F.; Qazi, Y.; Mulgaonkar, S.; McCague, K.; Patel, D.; Peddi, V.R.; Shaffer, D. Association of clinical events with everolimus exposure in kidney transplant patients receiving low doses of tacrolimus. Am. J. Transplant. 2017, 17, 2363-2371. [CrossRef] [PubMed]

10. Kirchner, G.I.; Meier-Wiedenbach, I.; Manns, M.P. Clinical pharmacokinetics of everolimus. Clin. Pharmacokinet. 2004, 43, 83-95. [CrossRef] [PubMed]

11. Moes, D.J.; Press, R.R.; den Hartigh, J.; van der Straaten, T.; de Fijter, J.W.; Guchelaar, H.J. Population pharmacokinetics and pharmacogenetics of everolimus in renal transplant patients. Clin. Pharmacokinet. 2012, 51, 467-480. [CrossRef] [PubMed]

12. Hesselink, D.A.; Bouamar, R.; Elens, L.; van Schaik, R.H.; van Gelder, T. The role of pharmacogenetics in the disposition of and response to tacrolimus in solid organ transplantation. Clin. Pharmacokinet. 2014, 53, 123-139. [CrossRef] [PubMed]

13. Moes, D.J.; Swen, J.J.; den Hartigh, J.; van der Straaten, T.; van der Heide, J.J.; Sanders, J.S.; Bemelman, F.J.; de Fijter, J.W.; Guchelaar, H.J. Effect of CYP3A4*22, CYP3A5*3, and CYP3A combined genotypes on cyclosporine, everolimus, and tacrolimus pharmacokinetics in renal transplantation. CPT Pharmacomet. Syst. Pharmacol. 2014, 3, e100. [CrossRef] [PubMed]

14. Hiratsuka, M.; Takekuma, Y.; Endo, N.; Narahara, K.; Hamdy, S.I.; Kishikawa, Y.; Matsuura, M.; Agatsuma, Y.; Inoue, T.; Mizugaki, M. Allele and genotype frequencies of CYP2B6 and CYP3A5 in the Japanese population. Eur. J. Clin. Pharmacol. 2002, 58, 417-421. [CrossRef] [PubMed]

15. Niioka, T.; Kagaya, H.; Saito, M.; Inoue, T.; Numakura, K.; Yamamoto, R.; Akamine, Y.; Habuchi, T.; Satoh, S.; Miura, M. Influence of everolimus on the pharmacokinetics of tacrolimus in Japanese renal transplant patients. Int. J. Urol. 2016, 23, 484-490. [CrossRef] [PubMed]

16. Picard, N.; Rouguieg-Malki, K.; Kamar, N.; Rostaing, L.; Marquet, P. CYP3A5 genotype does not influence everolimus in vitro metabolism and clinical pharmacokinetics in renal transplant recipients. Transplantation 2011, 91, 652-656. [CrossRef] [PubMed]

17. Thummel, K.E.; O'Shea, D.; Paine, M.F.; Shen, D.D.; Kunze, K.L.; Perkins, J.D.; Wilkinson, G.R. Oral first-pass elimination of midazolam involves both gastrointestinal and hepatic CYP3A-mediated metabolism. Clin. Pharmacol. Ther. 1996, 59, 491-502. [CrossRef]

18. Gorski, J.C.; Jones, D.R.; Haehner-Daniels, B.D.; Hamman, M.A.; O'Mara, E.M., Jr.; Hall, S.D. The contribution of intestinal and hepatic CYP3A to the interaction between midazolam and clarithromycin. Clin. Pharmacol. Ther. 1998, 64, 133-143. [CrossRef]

19. De Jonge, H.; de Loor, H.; Verbeke, K.; Vanrenterghem, Y.; Kuypers, D.R. In vivo CYP3A4 activity, CYP3A5 genotype, and hematocrit predict tacrolimus dose requirements and clearance in renal transplant patients. Clin. Pharmacol. Ther. 2012, 92, 366-375. [CrossRef] [PubMed]

20. De Jonge, H.; Vanhove, T.; de Loor, H.; Verbeke, K.; Kuypers, D.R. Progressive decline in tacrolimus clearance after renal transplantation is partially explained by decreasing CYP3A4 activity and increasing haematocrit. Br. J. Clin. Pharmacol. 2015, 80, 548-559. [CrossRef] [PubMed]

21. Niioka, T.; Kagaya, H.; Miura, M.; Numakura, K.; Saito, M.; Inoue, T.; Habuchi, T.; Satoh, S. Pharmaceutical and genetic determinants for interindividual differences of tacrolimus bioavailability in renal transplant recipients. Eur. J. Clin. Pharmacol. 2013, 69, 1659-1665. [CrossRef] [PubMed]

22. Satoh, S.; Niioka, T.; Kagaya, H.; Numakura, K.; Inoue, T.; Saito, M.; Komine, N.; Narita, S.; Tsuchiya, N.; Habuchi, T.; et al. Pharmacokinetic and CYP3A5 pharmacogenetic differences between once- and twice-daily tacrolimus from the first dosing day to 1 year after renal transplantation. Pharmacogenomics 2014, 15, 1495-1506. [CrossRef] [PubMed] 
23. Vanhove, T.; Bouillon, T.; de Loor, H.; Annaert, P.; Kuypers, D. Fexofenadine, a Putative In Vivo P-glycoprotein Probe, Fails to Predict Clearance of the Substrate Tacrolimus in Renal Recipients. Clin. Pharmacol. Ther. 2017. [CrossRef] [PubMed]

24. Staatz, C.E.; Goodman, L.K.; Tett, S.E. Effect of CYP3A and ABCB1 single nucleotide polymorphisms on the pharmacokinetics and pharmacodynamics of calcineurin inhibitors: Part II. Clin. Pharmacokinet. 2010, 49, 207-221. [CrossRef] [PubMed]

25. Staatz, C.E.; Goodman, L.K.; Tett, S.E. Effect of CYP3A and ABCB1 single nucleotide polymorphisms on the pharmacokinetics and pharmacodynamics of calcineurin inhibitors: Part I. Clin. Pharmacokinet. 2010, 49, 141-175. [CrossRef] [PubMed]

26. Lemaitre, F.; Bezian, E.; Goldwirt, L.; Fernandez, C.; Farinotti, R.; Varnous, S.; Urien, S.; Antignac, M. Population pharmacokinetics of everolimus in cardiac recipients: comedications, ABCB1, and CYP3A5 polymorphisms. Ther. Drug Monit. 2012, 34, 686-694. [CrossRef] [PubMed]

27. Tsuchiya, N.; Satoh, S.; Tada, H.; Li, Z.; Ohyama, C.; Sato, K.; Suzuki, T.; Habuchi, T.; Kato, T. Influence of CYP3A5 and MDR1 (ABCB1) Polymorphisms on the Pharmacokinetics of Tacrolimus in Renal Transplant Recipients. Transplantation 2004, 78, 1182-1187. [CrossRef] [PubMed]

(C) 2018 by the authors. Licensee MDPI, Basel, Switzerland. This article is an open access article distributed under the terms and conditions of the Creative Commons Attribution (CC BY) license (http:/ / creativecommons.org/licenses/by/4.0/). 